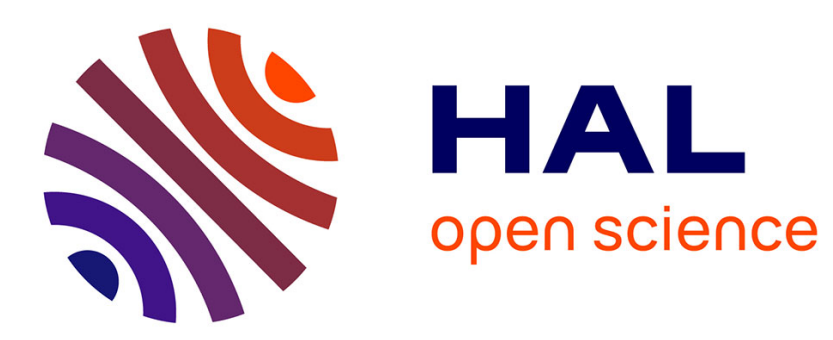

\title{
The Bordoni Relaxation in High Purity Copper Single Crystals at Low Frequencies
}

\author{
A. Ghilarducci, A. Moreno-Gobbi, M. Marotti, J. Eiras
}

\section{To cite this version:}

A. Ghilarducci, A. Moreno-Gobbi, M. Marotti, J. Eiras. The Bordoni Relaxation in High Purity Copper Single Crystals at Low Frequencies. Journal de Physique IV Proceedings, 1996, 06 (C8), pp.C8-211-C8-214. 10.1051/jp4:1996844 . jpa-00254652

\section{HAL Id: jpa-00254652 https://hal.science/jpa-00254652}

Submitted on 1 Jan 1996

HAL is a multi-disciplinary open access archive for the deposit and dissemination of scientific research documents, whether they are published or not. The documents may come from teaching and research institutions in France or abroad, or from public or private research centers.
L'archive ouverte pluridisciplinaire HAL, est destinée au dépôt et à la diffusion de documents scientifiques de niveau recherche, publiés ou non, émanant des établissements d'enseignement et de recherche français ou étrangers, des laboratoires publics ou privés. 


\title{
The Bordoni Relaxation in High Purity Copper Single Crystals at Low Frequencies
}

\author{
A. Ghilarducci, A. Moreno-Gobbi*, M. Marotti* and J.A. Eiras** \\ Centro Atómico CC. 439, 8400 Bariloche RN, Argentina \\ * Inst. de Física, Fac. de Ciencias, Tristán Narvaja, 1674 Montevideo, Uruguay \\ ** Dept. de Física, UFSCar-Rod,Washington Luiz km 235, Sao Carlos SP, Brazil
}

\begin{abstract}
The aim of this work is to explore the low-frequency spectrum of $5 \mathrm{~N}$ pure copper in a subresonant pendulum which allows "in situ" cycled torsion deformation and recovery. Samples were taken from the same single crystals used for ultrasonic attenuation studies in order to compare both results in an Arrhenius plot.

In one sample prepared by electro-erosion, polished with nitric acid, recovered 4 hours at $650^{\circ} \mathrm{C}$ in preliminary vacuum and 1, 4 and $9 \%$ deformed at room temperature, the spectra show a main Bordoni peak whose height increases with deformation, and additional peaks in the $40-65 \mathrm{~K}$ range, as important as the Bordoni peak, which are due to impurities generated during the preparation of the sample.

In an uncontaminated sample cut by diamond disk, polished with a mixture of nitric, phosphoric and glacial acetic acids, and water, recovered in $5.10^{-6} \mathrm{mmHg}$ vacuum, deformed 3 and $5 \%$, the internal friction spectra show the main Bordoni peak as the principal effect, accompanied by a defect modulus.

The study of the influence of different parameters such as the amount of deformation, the amplitude and frequency of oscillation, the temperature rate and the recoveries may be an interesting contribution to the characterization of the Bordoni peak.
\end{abstract}

\section{INTRODUCTION}

The experimental width of the high-frequency (MHz) Bordoni peaks (BP) [2] is about 2.5 times a Debye peak, as Moreno-Gobbi and Eiras [1] reported, and also shows an asymmetry which increases at lower plastic sample deformations and high frequencies. Moreno-Gobbi and Eiras pointed out that if a resonant mechanism is added to the relaxation mechanism, considered as a single process with a Debye relaxation time, it is possible to explain the asymmetry of the high-frequencies BPs [3], remaining the width of the BPs a problem. Seeger [4], incorporating a diffusion mechanism in the kink-pairs creation process, obtained a relaxation time depending on temperature in the pre-exponential factor and also on the exponential term, from an equivalent creation enthalpy which is temperature-dependent. An interesting consequence of this relaxation time is the widening of the theoretical relaxation process. When the resonance mechanism is added to this process, it is possible to explain simultaneously the asymmetry and the large width of the high-frequency BPs, as Moreno-Gobbi et al, working on a $20 \%$ deformed highpurity copper sample show [5]. But this diffusion kink theory does not have an unquestionable experimental evidence, as Richie and Fantozzi [6] recently pointed out. Moreno-Gobbi et al. [7] shown that a slope of $0.08 \mathrm{eV}$ exists in the high frequency Arrhenius plot, lower than the slope obtained with intermediate and low frequencies data from the literature, $0.12 \mathrm{eV}[1,6]$, in accordance with Seeger prediction. However they recognized the importance of new measurements made in the low-Hz frequency range, wich were on samples similar to those used in high-frequency measurements in order to obtain less dispersion than the literature data show, looking for a better confirmation of the diffusion mechanism. 


\section{EXPERIMENTAL PROCEDURE}

Two different samples were prepared, cut from the same crystals used by Moreno-Gobbi and Eiras [1] in high frequency measurements. The samples were oriented maintaining their major faces in perpendicular to the (111) direction. The sub-resonant torsion pendulum [9] from the Internal Friction Laboratory at CAB was used to obtain the internal friction and shear modulus as a function of temperature.

The first sample with dimensions $20,00 \times 2,50 \times 0,90 \mathrm{~mm}( \pm 0,05 \mathrm{~mm})$, was cut by an electro-erosion technique, and submitted to a chemical attack with aqueous nitric acid solution in order to take out the superficial layer. It was later recovered at $650^{\circ} \mathrm{C}$ for an hour and then cooled very slowly during 5 hours in preliminary vacuum; the sample was regulated in stages of 50 degrees each hour until $0^{\circ} \mathrm{C}$. It was then placed in the pendulum and was plastically deformed at room temperature by torsion until $1 \%$. Immediate measurements at different frequencies were made. After this a new deformation of $3 \%$ was effected on the sample, arriving at a total of $4 \%$ plastic deformation. A new series of measurements was made and then the deformation process was repeated until $9 \%$ accumulated deformation on the sample was obtained. At this deformation degree measurements was made.

A second sample, whose dimensions were $19,55 \times 2,45 \times 0,90 \mathrm{~mm}( \pm 0,05 \mathrm{~mm})$, was cut from the same crystal with a diamond disc and submitted to chemical attack with a solution in water of $55 \mathrm{ml}$ phosphoric acid $\mathrm{NH}_{3} \mathrm{PO}_{4}, 20 \mathrm{ml}$ of nitric acid $\mathrm{HNO}_{3}$ and $25 \mathrm{ml}$ of glacial acid $\mathrm{AcOH}$ It was recovered in $5.10^{-6}$ mmHg vacuum in a similar way to the first sample. All other thermal and mechanical treatments done on this second sample were similar to those done on the first one, but in this case the accumulated deformations were of 1,3 and $5 \%$.

Measurements of internal friction and modulus were made at 2, 5, 10 and $20 \mathrm{~Hz}$. Measurement cycles, cooling and heating the sample between 20 and $273 \mathrm{~K}$ at a maximum rate of $1 \mathrm{~K} / \mathrm{min}$, were made. Every time room temperature was reached, the sample was submitted to a thermal treatment of 1 hour at $373 \mathrm{~K}$. For every deformation step this process was repeated.

Some representative measurements of the first sample series are showen in figures $1 \mathrm{a}$ and $1 \mathrm{~b}$, and in figures $2 \mathrm{a}$ and $2 \mathrm{~b}$ for the second sample.

\section{DISCUSSION}

The measurements done with the electro-erosion cut sample show an unexpected behavior between the first and the second BP when the sample was heated from 20 to $65 \mathrm{~K}$. Starting from the second BP, the internal friction (IF) curve rises with a slope greater than the corresponding one in usual IF curves. On all measurements done, independently of the measurement frequency, at $62 \mathrm{~K}$ the IF falls down to the first BP.

The IF curves, measured on the sample cut with a diamond disc, show the usual behavior. Their BPs temperatures were presented in this paper in order to obtain an Arrhenius plot. They were slightly lower than those obtained from the first measurements.

Two representative curves of internal friction as a function of the temperature measured on the first sample are shown in figures $1 \mathrm{a}$ and $1 \mathrm{~b}$.

Both curves were measured at $5 \mathrm{~Hz}$ on the first sample, deformed at $5 \%$ at room temperature. In fig. 1a the sample was heated from 20 to $200 \mathrm{~K}$. It shows the unexpected behavior mentioned above between 40 and $65 \mathrm{~K}$. In figure $1 \mathrm{~b}$ the sample was cooled from 273 to $20 \mathrm{~K}$. In this figure we can see only the first and second BPs without the spurious behavior of fig. $1 \mathrm{a}$. 


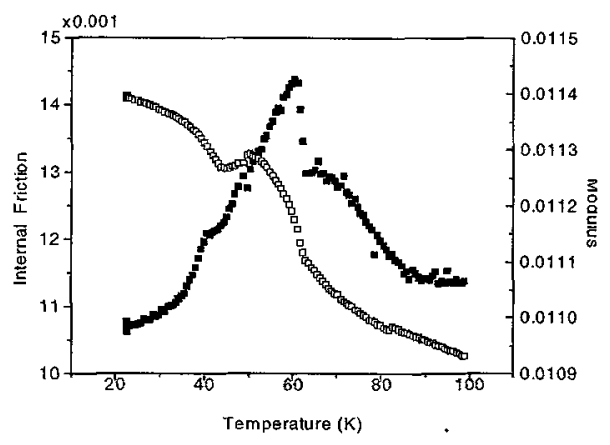

Figure 1a. Full squares: internal friction measured at $5 \mathrm{~Hz}$, on a sample cut by electro-erosion and plastically deformed at $5 \%$ at room temperature and recovered $1 \mathrm{~h}$ at $373 \mathrm{~K}$. The sample was heated from $20 \mathrm{~K}$ to $200 \mathrm{~K}$ at a maximum rate of $1 \mathrm{~K} / \mathrm{min}$. It shows an unexpected behavior between 40 and $60 \mathrm{~K}$, approximately. Open squares: magnitude proportional to the associated elastic modulus, showing a hardening in the region of the unexpected internal friction behavior.

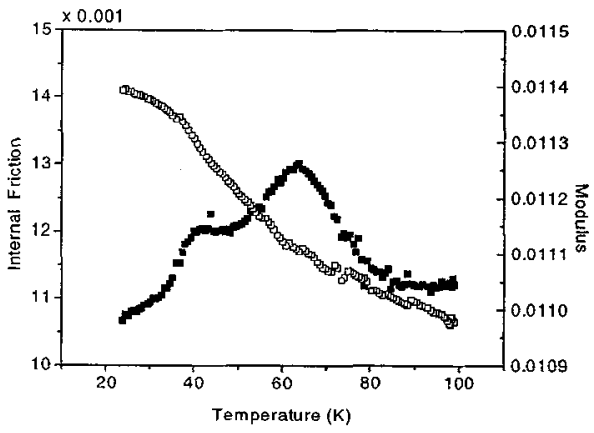

Figure 1b. Full squares: Internal friction measured in identical conditions as those of figure $1 \mathrm{a}$, but cooling the sample from $273 \mathrm{~K}$ to $20 \mathrm{~K}$ at a rate of $1 \mathrm{~K} / \mathrm{min}$. This curve shows the behavior reported in the literature for high purity samples. Open squares: magnitude proportional to the associated elastic modulus, not showing the hardening process of fig. 1a.

Two representative curves of the second series of measurements are shown in figure $2 \mathrm{a}$ and $2 \mathrm{~b}$. Both curves were measured at $5 \mathrm{~Hz}$ on the $5 \%$ room temperature deformed second sample. In fig. $2 \mathrm{a}$. the sample was cooled from 273 to $20 \mathrm{~K}$. In figure $2 \mathrm{~b}$ the sample was heated from 20 to $200 \mathrm{~K}$. In both curves we can see only the first and second Bordoni peaks within the spurious behavior of fig. $1 \mathrm{a}$.

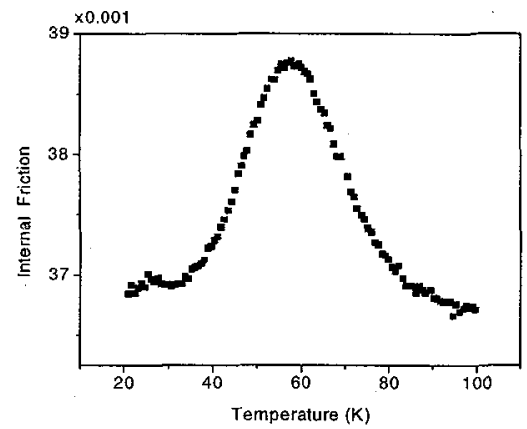

Figure 2a. Internal friction measured at $20 \mathrm{~Hz}$, on a sample cut with a diamond disc. The sample was plastically deformed at 5\% at room temperature recovered $1 \mathrm{hr}$ at $373 \mathrm{~K}$, and measured during cooling from $273 \mathrm{~K}$ to $20 \mathrm{~K}$ at a rate of $1 \mathrm{~K} / \mathrm{min}$.

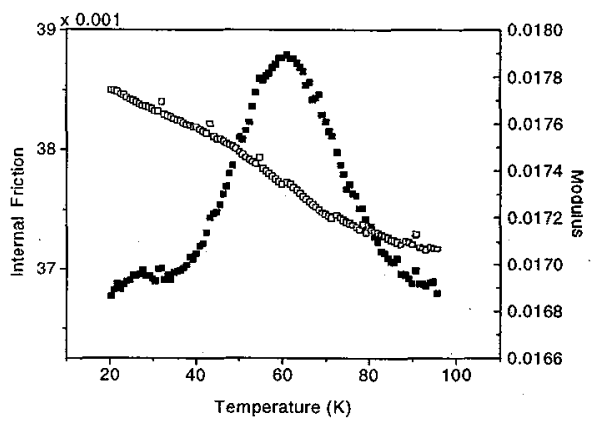

Figure 2b. Full squares: Internal friction measured at $20 \mathrm{~Hz}$, in identical conditions to those of figure $2 \mathrm{a}$, but heated from $20 \mathrm{~K}$ to $273 \mathrm{~K}$ at a rate of $1 \mathrm{~K} / \mathrm{min}$ and not showing the unexpected behavior of fig. 1a. Open squares: magnitude proportional to the associated elastic modulus, not showing the hardening process in fig. la. 
When the sample was cooled or heated a slight difference between the peak temperatures from the second series was obtained. The average temperature was adopted as the real peak temperature

Figure 3 shows an Arrhenius plot with peak temperature obtained with the average peak temperatures from cooling and heating data obtained from the second series of measurements. From this plot we obtain a low temperature activation enthalpy of $0.12 \mathrm{eV}$.

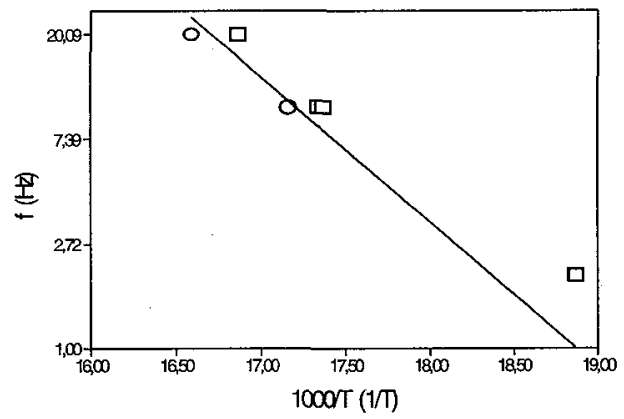

Figure 3. Arrhenius plot showing peak temperaturas obtained for this work with the second series of measurements, on samples deformed in: squares, $3 \%$ and circles, 5\%. Continuos line: fitted line, assuming a Debye process. The activation enthalpy obtained from this plot is of $0.12 \mathrm{eV}$.

\section{CONCLUSION}

A new low frequency $(2-20 \mathrm{~Hz})$ Bordoni Peak characterization was made. Two samples were cut from a high purity copper crystal to obtain low frequency measurements. The first sample was cut by electroerosion and the second sample with a diamond disc. When measurements were done on the first sample heating it from 5 to $200 \mathrm{~K}$, an unexpected behavior between the first and the second BP was obtained. However a normal behavior is reported when measurements were done heating the second sample.

When the sample was cut by electro-erosion, an spurious behavior was found when measurements were done heating the sample. It is shown here in order to prevent futur experimentators to take care with sample preparation, as well to make attention on BP sensibility on low impurity contents.

New low frequency temperature peaks are reported. These are very important in order to check the main consequence of the diffusion mechanism in kink pairs creation, which is the existence of a temperature dependent equivalent enthalpy, as proposed by Seeger. These is done in another paper [8].

\section{References}

[1] Moreno-Gobbi, A. and Eiras, J. A., Mater.Sci Forum, 119 -120 (1993) 189.

[2] Bordoni, P. G., Ric Sci., 19 (1949) 851

[3] Moreno-Gobbi, A. and Eiras, J. A., Jour.Alloys and Comp., 211-212 (1994) $152 .$.

[4] Seeger, A., J. Physique, 42 (1981) C5-201.

[5] Moreno-Gobbi, A., Eiras, J. A. and Marotti, M.. Submitted.

[6] Richie, Y., Fantozzi, G., Internal Friction due to the Intrinsic Propierties of Dislocations in Metals: Kink Relaxation, in Dislocations in Solids, ed. by F.R.N. Nabarro, chap.45, Elseiver Sci. Publ., 1992.

[7] Moreno-Gobbi, A., Eiras, J. A. and Marotti, M.. Submitted.

[8] Moreno-Gobbi, A., Eiras, J. A., Marotti, M. and Ghilarducci, A., Proceeding from 11 ICIFUAS, France 1996.

[9] D’Anna, G., Benoit, W. Rev. Sci. Instrum. 61, 12 (1990) 3821. 